\title{
A new species of Phymatodes Mulsant (Coleoptera, Cerambycidae) from China
}

\author{
Shulin Yang ${ }^{1, \dagger}$ \\ I School of Life Sciences, Guizhou Normal University, Guiyang, Guizhou China 550001 \\ † http://zoobank.org/ODACC320-5021-41A1-A99E-B1730B9D1DEC \\ Corresponding author: Shulin Yang (s.yang@gznu.edu.cn)
}

Academic editor: S. Lingafelter | Received 11 June 2013 | Accepted 1 November 2013 | Published 6 January 2014

http://zoobank.org/976D9238-0AAB-4B7F-AEE3-3E67304B32C9

Citation: Yang S (2013) A new species of Phymatodes Mulsant (Coleoptera, Cerambycidae) from China. ZooKeys 367: 11-17. doi: 10.3897/zookeys.367.5774

\begin{abstract}
A new species, Phymatodes (Poecilium) latefasciatus, sp. n. (Coleoptera, Cerambycidae, Cerambycinae, Callidiini) from China is described and illustrated. Features distinguishing the new species from its congeners are presented.
\end{abstract}

\section{Keywords}

Guizhou, longhorn beetles, taxonomy

\section{Introduction}

Phymatodes Mulsant, 1839 is a genus in the tribe Callidiini Mulsant, 1839. Nearly 70 species of Phymatodes have been recorded around the world. There are 32 species described from the Palearctic region (Rapuzzi and Sama 2009, Löbl and Smetana 2010, Danilevsky 2010b, Sama et al. 2011). Gressitt (1951) recorded 10 Phymatodes species (actually 9 species) from China in subgenera, Phymatodellus, Paraphymatodes and Poecilium. The 10 species were Phymatodes (Phymatodellus) kozlovi Semenov \& Plavilstshikov, 1936, P. (Phymatodellus) semenovi Plavilstshikov, 1935, P. (Phymatodellus) sinensis (Pic, 1900), P. (Phymatodellus) ussuricus Plavilstshikov, 1940, P. (Paraphymatodes) albicinctus (Bates, 1873), P. (Paraphymatodes) hauseri (Pic, 1907), P. (Paraphymatodes) 
mediofasciatum (Pic, 1933), P. (Poecilium) infasciatus Pic, 1935, P. (Poecilium) maaki (Kraatz, 1879), P. (Poecilium) savioi Pic, 1935. Afterwards, P. (Phymatodellus) ussuricus Plavilstshikov, 1940 was treated as a synonym of P. (Phymatodellus) infasciatus Pic, 1935 (Hua 1982), and four new species were described in the genus: $P$. (Poecilium) mizunumai Hayashi, 1974, P. (Poecilium) eximium Holzschuh, 1995, P. (Phymatodellus) jiangi Wang \& Zheng, 2003, P. (Phymatodellus) ahenum Holzschuh, 2007. Totally 13 Phymatodes species are distributed in China.

Gressitt (1951) placed Chinese Phymatodes species in subgenus Poecilium by characters: elytra with a cluster of long erect hairs behind scutellum, reddish at base and blackish posteriorly, generally with two subobliquely transverse pale bands; eyes nearly divided by emargination. Ohbayashi and Niisato (2007) divided Japanese Phymatodes species into subgenus Poecilium by fewer characters: roughly equal length of first hind tarsal segment to total length of second and third segments; and presence of two elytral bands. Löbl and Smetana (2010) elevated the subgenus Poecilium to genus with subgenera Paraphymatodes and Phymatoderus as its synonyms. Later, Poecilium was re-placed as subgenus (Danilevsky 2010a). In this study, Poecilium is considered as a subgenus of Phymatodes by a synthesis of characters of Gressitt (1951) and Ohbayashi and Niisato (2007).

According to the above characters, currently, there are totally nine species in the subgenus Poecilium. Among the 13 Chinese Phymatodes species, P. maaki (Kraatz, 1879), P. savioi Pic, 1935, P. mizunumai Hayashi, 1974, and P. eximium Holzschuh, 1995 are recognized in subgenus Poecilium. Besides the four Chinese species, five other species in subgenus Poecilium were recorded: P. alni (Linné, 1767) (distribution: Europe; Asia: Kazakhstan, Turkey), P. antonini Rapuzzi, Sama \& Tichy, 2011 (distribution: Syria), P. ermolenkoi (Tsherepanov, 1980) (distribution: Russia: Primorskii Krai Province), P. kasnaki Sama, 2011 (distribution: Turkey), and P. quadrimaculatum Gressitt, 1935 (distribution: Japan).

Recently, specimens representing a new species of Phymatodes from Guizhou province of China were discovered and it fits into the subgenus Poecilium according to aforementioned characters. The new species is described herein.

The collection acronyms used in the text are as follows:

GZNULS School of Life Sciences, Guizhou Normal University, Guiyang, Guizhou China.

\section{Taxonomy}

\section{Phymatodes (Poecilium) latefasciatus sp. $\mathbf{n}$.} http://zoobank.org/DB67D24A-8EAC-4613-861B-48E72B23D6A0 http://species-id.net/wiki/Phymatodes_latefasciatus Figure 1

Etymology. The name refers to the second elytral band which is gradually widening toward suture after mid-point. 
Diagnosis. Characters of the new species conform with all established characters of subgenus Poecilium, elytra with a cluster of long erect hairs behind scutellum, reddish at base and blackish posteriorly, with two pale bands; eyes nearly divided by emargination; ratio of first hind tarsal segment's length to total length of second and third segments nearly 1:1 (Gressitt 1951, Ohbayashi and Niisato 2007). Thus, it is placed in the subgenus Poecilium.

Phymatodes (Poecilium) latefasciatus sp. $\mathrm{n}$. is distinguished from its congeners by the combination of the following characters: shape of the second elytral band; proportion of reddish brown area on basal elytron to the whole elytron; the color of antennae; and shapes of swelling part of femur. P. latefasciatus can be distinguished from all other congeners by the shape of its $2^{\text {nd }}$ elytral band which is gradually widening towards suture after mid-point (Fig 1a). In addition to this most obvious one, other characters distinguish the new species from three other morphologically close Chinese species in the same subgenus: P. (Poecilium) maaki (Kraatz, 1879) (distribution: China: Heilongjiang, Jiangxi, Sichuan, Taiwan; Russia: Far East; Korea, Japan) (Kraatz 1879, Hua 2002, Löbl and Smetana 2010); P. (Poecilium) savioi Pic, 1935 (distribution: China: Jiangxi, Shanghai) (Pic 1935, Hua 2002, Löbl and Smetana 2010); and $P$. (Poecilium) mizunumai Hayashi, 1974 (distribution: Taiwan) (Hayashi 1974, Hua 2002, Chou 2008, Löbl and Smetana 2010). The new species is also different from $P$. maaki (Kraatz, 1879), a species most similar to the new species, by these characters: 1) proportion of the size of reddish brown area on elytral base to the whole elytron smaller, approximately $1 / 3 ; 2$ ) antenna black; 3) clubbed part of meso-femora and hind femora shorter comparing to length of whole femur, suddenly swelling toward tibiae after middle. Beside shape of second elytral band, P. latefasciatus also differs from P. savioi Pic, 1935 by characters: 1) smaller proportion of reddish brown basal elytral area; 2) antenna black; 3) elytral bands ivory not yellowish, and first band not reaching suture. As the above two species, three other characters are also used to distinguish $P$. latefasciatus from P. mizunumai Hayashi, 1974, 1) antenna black; 2) first elytral band nearly transverse, not arcuate and shape as a caret symbol; 3) ratio of femoral clubbed part to femoral basal part larger.

Description. Female (male unknown). Moderate body size, length $8.4-8.5 \mathrm{~mm}$ (holotype $8.4 \mathrm{~mm}$ ), width $2.9-3.2 \mathrm{~mm}$ (measured across humeri, holotype $2.9 \mathrm{~mm}$ ). Yellowish-brown, head, prothorax, swollen part of femurs black, antennae and tibiae lighter, basal part of elytra (ca 1/3 of total elytral length) reddish brown, the rest black, two subobliquely transverse ivory bands on each elytron.

Front nearly flat, transverse; head slightly concave between antennal tubercles which are slightly raised and separated by approximately the width of one antennal socket, front and vertex with sparse punctures and short yellow pubescences on some of these punctures; eyes coarsely-faceted; scape and antennomere 2 with semi-erect long yellow hairs, rest of the antennomeres covered with short dark brown hairs, antennomeres 2, 3 and 4 with sparse long yellow hairs especially at tips, relatively long yellow hairs also presenting at ends of antennomeres 5 to 10 but length gradually reduced by antenna segment; outer tips of antennomeres 6 to 10 slightly serrated. 

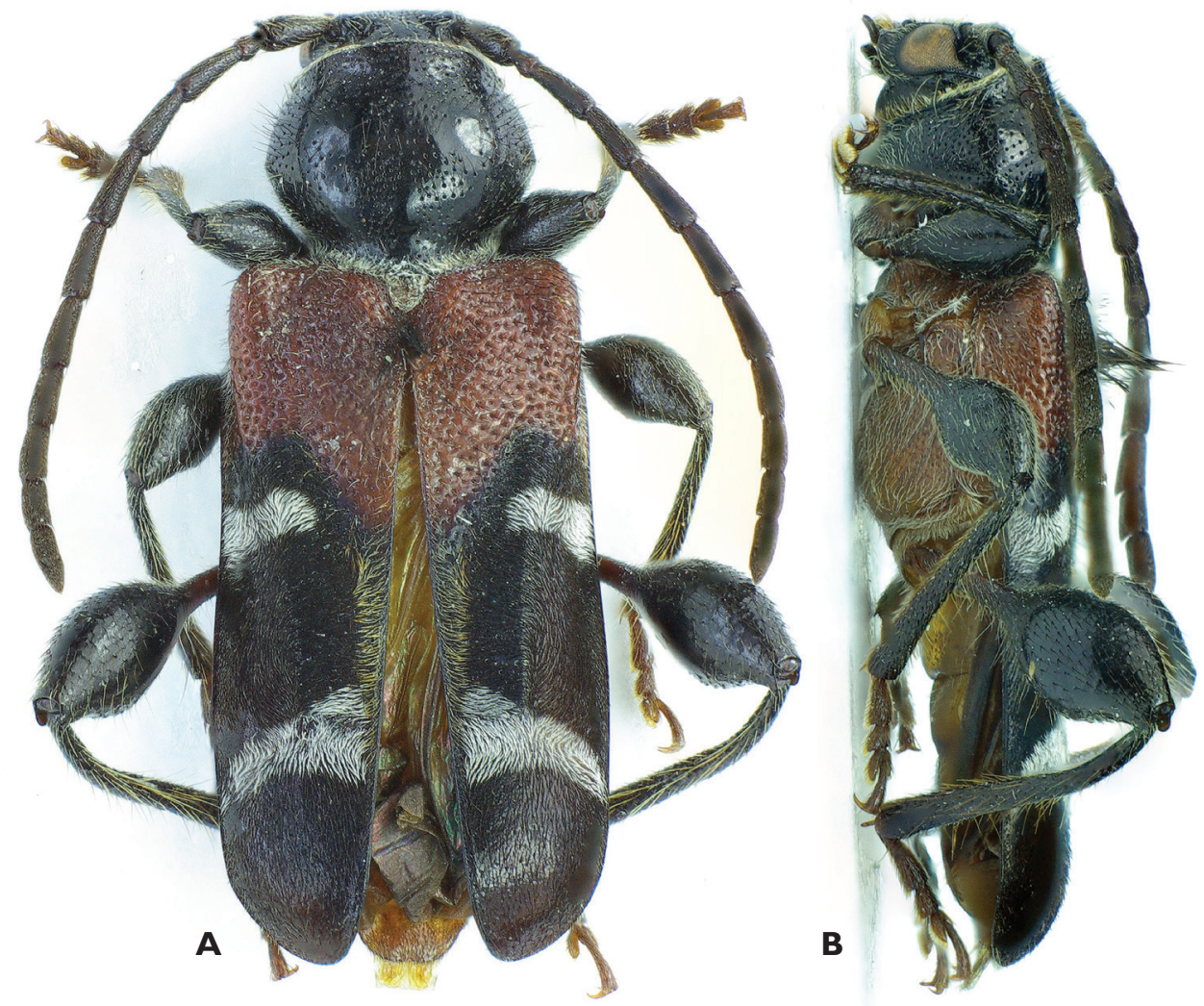

Figure I. Phymatodes (Poecilium) latefasciatus, sp. n. A dorsal view B lateral view.

Prothorax transverse, approximately 1.2 times wide as long, widest and slightly angulated laterally near middle, contracting towards base and narrowest at base; pronotum slightly convex, shining, with irregular punctures and covered with moderately long erect black setae; short thick pale yellow hairs at collar edge and base of pronotum, forming a narrow transverse strip at the base; prosternal intercoxal process short, spine shaped, not reaching coxal middle; scutellum reddish yellow, length longer than width, nearly rectangle, semicircular at end.

Elytron long, approximately 4 times as basal width, parallel sided, with rounded apex; basal third red brown area irregularly dense punctured, with erect hairs, a cluster of long erect brown hairs after scutellum; rest of the elytron covered with dense black hairs except two nearly transverse ivory bands and a narrow golden strip lengthwisely along suture between the two bands; the first ivory band extending from elytral margin, approximately half of elytron width, not reaching suture; the second ivory band slightly curving towards base, gradually widening towards suture after mid-point of elytron, nearly reaching suture but interrupted by the lengthwisely golden strip.

Femora strongly swollen, fore-femur swollen gradually from near fore-coxa, mesofemur and hind femur swollen after approximately half of femoral length; legs cover 
with moderately long thick pale golden hairs, hair on tibiae longer and darker than that on femora; non-swollen part of femora reddish brown, swollen parts black; $1^{\text {st }}$ segment of hind tarsi short, approximately 1.2 times as long as $2^{\text {nd }}$ and $3^{\text {rd }}$ together.

Abdomen slightly shining with small punctures, with relatively sparse moderately long semi-erect pale yellow hairs.

Type material. Holotype $q$ from Heichong, Shibing County, Guizhou Province, CHINA, 2013.IV.17, $27^{\circ} 09.068^{\prime} \mathrm{N}, 108^{\circ} 07.384^{\prime} \mathrm{E}$, net sweeping on a Viburnum sp. plant, S. Yang col. (GZNULS). Paratype $q$ from Leigongshan, Leishan County, Guizhou Province, CHINA, $26^{\circ} 22.781^{\prime} \mathrm{N}, 108^{\circ} 11.534$ 'E, 2012.V.23, Lindgren funnel trap, S. Yang col. (GZNULS).

\section{Modified couplets to key to Chinese Phymatodes species of subgenus Poecilium}

A modified key to Phymatodes species of subgenus Poecilium is presented based on Gressitt's (1951, page 228) key to Chinese Phymatodes species. In his key, P. latefasciatus will run to couplet 8 . Couplets $8-9$ can be modified, as presented blow, to accommodate the new species and other species described in the subgenus after his key published.

8 Dark portions of elytra with two silvery white bands; first band subtransverse, not reaching suture

- $\quad$ Dark portions of elytra with two yellowish gray bands; first band arched; reaching suture; second band transverse; only hind femoral clubs pitchy

P. savioi Pic

9 Second elytral band subtransverse, reaching or nearly reaching suture, not caret symbol shaped

- $\quad$ Second elytral band oblique, not reaching suture, caret symbol shaped; front wrinkled with ridges .P. eximium Holzschuh

10 Width of whole second elytral band roughly constant, not gradually widening towards suture

- Width of whole second elytral band not constant, gradually widening towards suture after middle.

P. latefascitus Yang

11 First elytral band arcuate and acute angled as a caret symbol; ratio of femoral clubbed part to un-swelling femoral basal part smaller... P. mizunumai Hayashi

- $\quad$ First elytral band slightly bend smoothly, not acute angled as a caret symbol; ratio of femoral clubbed part to un-swelling femoral basal part larger

P. maaki Kraatz

\section{Acknowledgements}

The study is supported by the Research Foundation of Guizhou Normal University (Grant No. 11904-05032110004) and the Joint Fund of Guizhou Science and Technology De- 
partment and Guizhou Normal University (Grant No. 11904-0502211Y0106, 黔科合 J字LKS[2011]38号). I thank Xinming Zhu, Jijun Chen, Zhenguo Xie, Yongfu Yu and Shengguo Yang of the Leigongshan National Natural Reserve for their help in the field work, and Vitali Nagirnyi, Maxim Smirnov and Francesco Vitali for their help on specimen determination. I also thank Guiqiang Huang for his help on literature. I thank two reviewers, Steven Lingafelter and Olivier Gregory, for their help to improve the manuscript.

\section{References}

Bates HW (1873) On the Longicorn Coleoptera of Japan. The Annals and Magazine of Natural History, London (4), 12 (69): 193-201.

Chou WI (2008) The Atlas of Taiwanese Cerambycidae (2nd Ed.). Owl Publishing House, Taipei, 408 pp.

Danilevsky ML (2010a) Additions and corrections to the new Catalogue of Palaearctic Cerambycidae (Coleoptera). In: Löbl I, Smetana A (Eds) (2010) Russian Entomological Journal, 19 (3): 215-239.

Danilevsky ML (2010b) Phymatodes (Phymatoderus) vandae sp. n. from Greece (Coleoptera: Cerambycidae). Folia Heyrovskyana, series A 18(1-3): 67-80.

Gressitt JL (1935) New Japanese longicorn beetles (Coleoptera: Cerambycidae) Kontyû, Tokyo $9 \mathrm{~m}(4): 166-179$.

Gressitt JL (1951) Longicorn beetles of China. In: Lepesme P (Ed) Longicornia. Études et notes sur les longicornes. Volume II. Paul Lechevalier, Paris, 667 pp.

Hayashi M (1974) New and unrecorded longicorn beetles from Taiwan (Coleoptera ; Cerambycidae) I. Bulletin of the Osaka Jonan Women's Junior College (9): 1-36.

Holzschuh C (1995) Beschreibung von 65 neuen Bockkäfern aus Europa und Asien, vorwiegend aus China und Thailand (Coleoptera: Disteniidae und Cerambycidae). Schriftenreihe der Forstlichen Bundesversuchanstalt (FBVA-Berichte) 84: 1-63.

Holzschuh C (2007) Beschreibung von 80 neuen Bockkäfern aus der orientalischen und palaearktischen Region, vorwiegend aus China, Laos und Borneo (Coleoptera, Cerambycidae). Entomologica Basiliensa et Collectionis Frey 29: 177-286.

Hua L (1982) A Check List of the Longicorn Beetles of China (Coleoptera: Cerambycidae). Sun Yat-sen University Press, 158 pp.

Hua L (2002) List of Chinese Insects: Coleoptera, Strepsiptera, Megaloptera, Neuroptera, Raphidiodea, Mecoptera and Trichoptera, Volume 2. Sun Yat-sen University Press, 612 pp. Kraatz G (1879) Ueber die Bockkäfer Ost-Sibiriens, namentlich die von Christoph am Amur gesammelten. Deutsche entomologische Zeitschrift 23: 77-117.

Linné C (1767) Systema Naturæ Editio Duodecima Reformata. Laurent Salvius, Holmiæ 1 (2): 533-1327.

Löbl I, Smetana A (2010) Catalogue of Palaearctic Coleoptera: Chrysomeloidea. Vol. 6. Apollo Books, 924 pp.

Ohbayashi N, Niisato T (2007) Longicorn Beetles of Japan. Tokai University Press, Kanagawa, $818 \mathrm{pp}$. 
Pic M (1900) Contribution à l'étude des Cerambycidæ de Chine et du Japon. Annales de la Société Entomologique de Belgique, Bruxelles 44 (1): 16-19.

Pic M (1907) Notes entomologiques diverses (Suite). L'Échange, Revue Linnéenne 23: 104.

Pic M (1933) Nouveautés diverses. Mélanges Exotico-Entomologiques 62: 1-36.

Pic M (1935) Nouveautés diverses. Mélanges Exotico-Entomologiques 66: 1-36.

Plavilstshikov NN (1935) Eine neue Phymatodes-Art aus China (Col., Cerambycidae). Entomologischer Anzeiger 15: 18-20.

Rapuzzi P, Sama G (2009) Description of new Cerambycidae from Greece, Turkey, northern Syria and China (Insecta Coleoptera Cerambycidae). Quaderni di Studi e Notizie di Storia Naturale della Romagna 29: 181-188.

Rapuzzi P, Sama G,Tichy T (2011) Description of a new species of Poecilium Fairmaire, 1864 from Syria (Coleoptera: Cerambycidae). Munis Entomology \& Zoology 6 (2): 673-675.

Sama G, Jansson N, Avci M, Sarikaya O, Coskun M, Kayis T, Özdikmen H (2011) Preliminary Report on a Survey of the Saproxylic Beetle Fauna Living on Old Hollow Oaks (Quercus spp.) and Oak Wood in Turkey (Coleoptera: Cerambycidae). Munis Entomology \& Zoology 6(2): 819-831.

Semenov T-SAP, Plavistshikov NN (1936) Description de quelques Cérambycides nouveaux du Tibet et de la Mongolie. Eos Revista Española de Entomología 11: 389-394.

Tsherepanov AI (1980) New species of longicorn beetles (Cerambycidae, Coleoptera) from forests of Siberia. Nauka, Novosibirsk, 88-92. (Series "New and little known species of the fauna of Siberia. No 14.)

Wang Z (2003) Monographia of Original Colored Longicorn Beetles of China's Northeast. Jilin Science and Technology Publishing House, Jilin, 419 pp. 